\title{
Predictors of Survival Among Colorectal Cancer Patients in a Low Incidence Area
}

This article was published in the following Dove Press journal:

Cancer Management and Research

\author{
Nahla Azzam (iD) \\ Yazed AIRuthia $\mathbb{D}^{2,3}$ \\ Othman Alharbi ${ }^{1}$ \\ Abdulrahman Aljebreen (1D ${ }^{\prime}$ \\ Majid Almadi ${ }^{1,4}$ \\ Maryam Alarfaj ${ }^{5}$ \\ Khalid Alsaleh ${ }^{6}$ \\ Abdulaziz Almasoud (D) \\ Muhannad Alsharidah' \\ Sarah Alseneidi \\ Fatimah Alali' \\ Malak Alalwan' \\ 'Gastroenterology Division, Department \\ of Medicine, College of Medicine, King \\ Saud University, Riyadh, Saudi Arabia; \\ ${ }^{2}$ Department of Clinical Pharmacy, \\ College of Pharmacy, King Saud \\ University, Riyadh, Saudi Arabia; \\ ${ }^{3}$ Pharmacoeconomics Research Unit, \\ College of Pharmacy, King Saud \\ University, Riyadh, Saudi Arabia; ${ }^{4}$ Division \\ of Gastroenterology, The McGill \\ University Health Center, Montreal \\ General Hospital, McGill University, \\ Montreal, Canada; ${ }^{5}$ Department of \\ Pharmaceutical Care, King Saud \\ University Medical City, Riyadh, Saudi \\ Arabia; ${ }^{6}$ Department of Hematology/ \\ Oncology, College of Medicine, King Saud \\ University, Riyadh, Saudi Arabia
}

Correspondence: Yazed AIRuthia

Department of Clinical Pharmacy, College

of Pharmacy, King Saud University, Riyadh,

Saudi Arabia

Tel +966 I I 4677483

Fax +966II4677480

Email yazeed@ksu.edu.sa
Background: Colorectal cancer is the third most common malignancy in Saudi Arabia. The best therapeutic regimen for colorectal cancer is a matter of ongoing debate and data on its treatment in Saudi Arabia are limited.

Purpose: The objective of this study was to explore the predictors of survival and to compare the risk of mortality among colorectal cancer patients treated with different therapeutic modalities.

Patients and Methods: The study utilized data from the electronic colorectal cancer registry of a university-affiliated tertiary care hospital. The Kaplan-Meier survival analysis was used to estimate the survival rates over 36 months of follow-up across rectal and colon cancer patients as well as different sociodemographic and medical characteristics. Bivariate and multiple Cox proportional-hazards regressions were conducted to estimate the risk of mortality among rectal and colon cancer patients undergoing different treatments.

Results: The number of patients in the registry who were followed up for 36 months was 143 patients. The majority of patients had colon cancer (74.13\%). Rectal cancer patients had generally better survival estimates compared to their colon cancer counterparts. Colon cancer patients treated with chemotherapy had a significantly lower risk of mortality controlling for the use of surgery, radiotherapy, and other variables including age, gender, stage of cancer, and family history of colorectal cancer $(\mathrm{HR}=0.33 ; P=0.03)$. Additionally, colon cancer patients with a family history of colorectal cancer had significantly higher risk of mortality $(\mathrm{HR}=3.40 ; P=0.02)$. Conclusion: The findings of this study highlight the value of chemotherapy in managing colon cancer patients.

Keywords: colorectal cancer, surgery, chemotherapy, survival, Saudi Arabia

\section{Introduction}

Colorectal cancer is the first most frequent type of cancer in men and the second most frequent in women. ${ }^{1}$ According to the World Health Organization, 1.8 million people were diagnosed worldwide with colorectal cancer in $2018 .^{1,2}$ In the same year, colorectal cancer resulted in 862,000 deaths globally, making it the second leading cause of cancer-related mortality. ${ }^{1-3}$ The incidence of this disease varies markedly among different geographic regions. The highest incidence rates were observed in Europe, ${ }^{4}$ while the lowest rates were observed in Asia. ${ }^{5}$ However, a growing trend is seen in many low- and middle-income countries. ${ }^{6}$ In the Kingdom of Saudi Arabia, colorectal cancer is the third most common malignancy and one of the leading causes of cancer-related deaths. ${ }^{7}$ Moreover, colorectal cancer ageadjusted mortality has been increasing over the past few years, and this trend is likely to continue in the future. ${ }^{7}$ 
According to the National Saudi Cancer Registry, only 253 colorectal cancer cases were reported in 1994, but this number increased to 1033 cases in 2010 . The age-adjusted incidence has increased from 5.0/100,000 in 1994 to 9.6/ 100,000 in 2010, and to $11.1 / 100,000$ in $2012 .^{8,9}$ At the King Faisal Specialist Hospital and Research Center (Riyadh, Saudi Arabia) alone, 622 cases were diagnosed with colorectal cancer from 1975 to $1989 .{ }^{10}$ The five-year survival of colorectal cancer patients varies widely between countries, ranging from $28 \%$ in developing African and Asian countries to $60 \%$ in Japan, United States, and Switzerland, ${ }^{11-13}$ whereas five-year survival rate of approximately $44 \%$ was reported in Saudi Arabia between 2000 and 2004. ${ }^{14}$ In the United States, men are diagnosed at a younger age than women; however, in Saudi Arabia men are diagnosed at an older age compared to women. ${ }^{8}$ According to a study that was conducted at the King Faisal Specialist Hospital, the mean age of diagnosis for women was 47.8 years compared to 53.5 years for men. ${ }^{10}$ Although the same study suggested that the incidence of colorectal cancer in Saudi Arabia is higher in males (383 cases, 61.6\%) than in females (239 cases, $38.4 \%),{ }^{10}$ a recent analysis in 40 European countries demonstrated that the incidence and mortality rates are comparable in both sexes. ${ }^{15}$ In contrast, the five-year survival rate among Saudi male colorectal cancer patients $(41.0 \%)$ is significantly lower than their female counterparts $(50.6 \%){ }^{14}$

Metastasis of colorectal cancer affects the likelihood of survival dramatically. ${ }^{16,17}$ Recent studies in the Netherlands have found that approximately $15-25 \%$ of colorectal cancer patients had metastases at the time of diagnosis. ${ }^{18,19}$ In Saudi Arabia, similar rates, ranging from $16 \%$ to $29 \%$, have been reported. ${ }^{8}$ Distant metastases, together with the older age ( $\geq 65$ years), were found to be significant risk factors of mortality among Saudi patients with colorectal cancer, however, gender and the cancer grade were not associated with mortality. ${ }^{14}$

Several epidemiological studies have found that diabetes mellitus may increase the risk of various types of cancer, such as pancreatic and liver cancers. ${ }^{20,21}$ The presence of a link between diabetes and colorectal cancer was hypothesized more than 20 years ago, ${ }^{22}$ and was recently recognized by the American Diabetes Association. ${ }^{23}$ However, the correlation between these two pathologic conditions has not been confirmed, indicating that country-specific factors may be involved. ${ }^{24}$ Importantly, recent epidemiologic studies have demonstrated that diabetic patients affected by colorectal cancer have poorer overall survival rates compared to their nondiabetic counterparts, ${ }^{25,26}$ in particular when complications of diabetes were present. ${ }^{27}$ However, other studies did not identify a similar association. ${ }^{28,29}$

Several therapeutic options are currently used for colorectal cancer treatment. ${ }^{30}$ However, surgery is the most common approach, ${ }^{31}$ although the perception of ideal surgical technique differs between the Western and Asian countries. $^{32}$ Data available from Saudi Arabia indicate that rectal cancer patients undergoing curative surgery have a significantly higher survival rate, 54\%, compared to $5 \%$ for those not treated surgically. ${ }^{33}$ The use of chemotherapy was associated with better survival rates compared to patients who were only treated by surgery. ${ }^{34,35}$ Although more recent data indicate that only $5 \%$ of patients benefit from adjuvant chemotherapy, ${ }^{30}$ this type of treatment is strongly recommended in case of highgrade tumors. ${ }^{36}$ Interestingly, over a period of 20 years, from the 1980 s to 2000 s, the median survival rate of colorectal cancer patients increased almost three-fold, and this improvement has been attributed to a more frequent use of chemotherapy. ${ }^{37}$ Radiotherapy has also been shown to improve the survival rate and reduce the probability of tumor recurrence, but with the introduction of new treatment modalities, its use became controversial. ${ }^{38}$

In view of the existing controversies and the paucity of data on colorectal cancer treatment in Saudi Arabia, the objective of the present study was to explore the predictors of survival and compare the risk of mortality among a sample of colorectal cancer patients in the Kingdom who were treated with different therapeutic modalities.

\section{Materials and Methods Study Design}

The present study was designed as a retrospective cohort study. The data were extracted from an electronic colorectal cancer registry maintained in the division of gastroenterology in the department of medicine at a university-affiliated tertiary care hospital in Riyadh, Saudi Arabia. The registry included patients who were diagnosed with colorectal cancer since January 2014 based on colonoscopy and histological confirmation; patients were followed for 36 months. The study was approved by the institutional review board of the College of Medicine at King Saud University (approval number E-11-538). 
The retrieved information from the database included age, gender, history of smoking and alcohol, the presence of comorbidities (diabetes, hypertension, inflammatory bowel disease), family history of colorectal cancer, histological type of colorectal cancer (non-mucinous adenocarcinoma, mucinous adenocarcinoma, poorly differentiated tumor), number of polyps detected during the index colonoscopy, and the presence of metastases. The treatments were categorized as surgery, chemotherapy, and radiotherapy. No personal identifiers were collected and no patient interviews were involved; therefore, written informed consent form was waived per the institution policy. Moreover, the collected data were coded to protect the confidentiality of the patients in accordance with the ethical principles of the declaration of Helsinki.

\section{Statistical Analysis}

All statistical analyses were conducted using $\mathrm{SAS}^{\circledR}$ version 9.2 (SAS Inc., Cary, NC, USA). The survival analysis was conducted using the Kaplan-Meier method, and the survival estimates across different variables were compared by the log-rank test. In order to explore the predictors of survival among colorectal cancer patients, bivariate Cox proportional-hazards regressions were conducted among rectal and colon cancer patients separately. A multiple Cox proportional-hazards regression model was conducted among colon cancer patients to examine the impact of different treatment modalities (surgery, chemotherapy, and radiotherapy) on mortality controlling for age, gender, family history of colorectal cancer, number of polyps, and stage of cancer. Statistical significance was considered at $\alpha<0.05$, and $95 \%$ confidence intervals were reported for all hazard ratios.

\section{Results}

The study enrolled 143 patients, of which 106 (74.13\%) and $37(25.87 \%)$ had colon and rectal cancers, respectively. Approximately, $57 \%$ of the study sample were male and the mean age was $59.41 \pm 12.84$ years (Table 1 ). The most frequent comorbidities were diabetes (31.47\%), hypertension (32.87\%), and a small group of patients had inflammatory bowel disease $(2.79 \%)$. Only 21 patients $(14.69 \%)$ reported a family history of colorectal cancer (Table 1).

The most frequent tumor type was non-mucinous adenocarcinoma, which occurred in 134 patients (93.71\%) (Table 1). Mucinous adenocarcinoma and poorly differentiated adenocarcinoma were present in $2.79 \%$ and $3.49 \%$
Table I Baseline Characteristics of Study Sample

\begin{tabular}{|l|l|}
\hline Characteristic & N (\%) \\
\hline $\begin{array}{l}\text { Gender } \\
\text { Female }\end{array}$ & $82(57.34)$ \\
\hline Age, years (mean \pm SD) & $6 I(42.66)$ \\
Colon cancer & $59.41 \pm 12.84$ \\
Rectal cancer & $106(74.13)$ \\
\hline Comorbidities & $37(25.87)$ \\
\hline Diabetes & \\
Hypertension & $45(31.47)$ \\
Inflammatory bowel disease & $47(32.87)$ \\
\hline Family history of colorectal cancer & $4(2.79)$ \\
\hline Type of Colorectal Cancer & $21(14.69)$ \\
\hline Non-mucinous adenocarcinoma & \\
Mucinous adenocarcinoma & $134(93.7 I)$ \\
Poorly differentiated & $4(2.79)$ \\
\hline Number of polyps (mean \pm SD) & $5(3.49)$ \\
\hline Stage of Cancer & $0.91 \pm 1.93$ \\
\hline Stage I & \\
Stage II & $14(9.79)$ \\
Stage III & $40(27.97)$ \\
\hline Stage IV & $60(4 I .96)$ \\
\hline
\end{tabular}

Note: Data are presented as mean \pm standard deviation.

of patients, respectively. A large variation was seen in the number of polyps, with a mean of 0.91 , median of 0 , and interquartile range of 1 . Surgery and chemotherapy were the most often used therapeutic modalities, with 99 $(69.23 \%)$ and $96(67.13 \%)$ patients treated with these approaches, respectively. Fifteen patients (10.48\%) underwent radiotherapy, and always in combination with surgery and chemotherapy. Sixty-seven patients (46.85\%) underwent both surgery and chemotherapy; while the number of patients who either underwent surgery or chemotherapy only were 32 (22.38\%) and 29 (20.28\%) patients, respectively.

The overall survival rate of the study sample over the 36month follow-up period is shown in Figure 1. The median survival in months for diabetic patients across the four stages of cancer was significantly lower than their non-diabetic counterparts as shown in Table 2. Similarly, the median survival in months across the four stages of cancer was significantly lower among patients with a family history of colorectal cancer compared to their counterparts with no family history of colorectal cancer (Table 2). The overall survival rates of colorectal cancer patients are shown in 


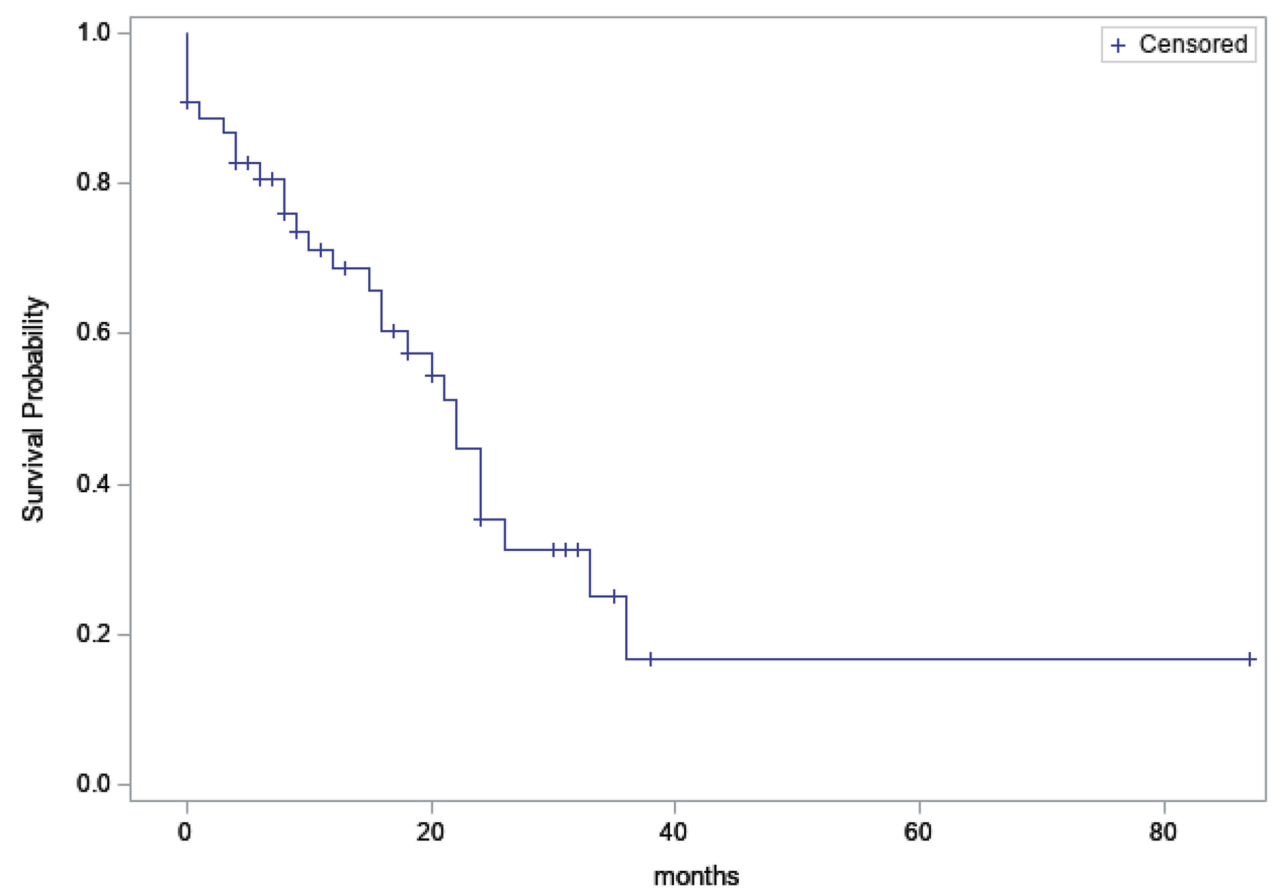

Figure I The survival rates of colorectal cancer patients over 36 months.

Figure 1 and the survival rates across different cancer stages are shown in Figure 2. Rectal cancer patients with stage III and IV had higher Kaplan-Meier (KM) survival estimates ( 0.751 and 0.540 , respectively) compared to their counterparts with colon cancer ( 0.366 and 0.120 , respectively) as shown in Table 3.

Neither surgery nor chemotherapy or radiotherapy were significantly associated with lower risk of mortality among rectal cancer patients as shown in Table 4. With the exception of family history of colorectal cancer, which was significantly associated with higher risk of mortality $(\mathrm{HR}=3.14 ; P=0.02)$, none of the tested variables in the bivariate Cox regression analysis was significantly associated with the risk of mortality among colon cancer patients as shown in Table 5. Moreover, the risk of mortality was not significantly associated with either surgery $(\mathrm{HR}=0.84 ; P=0.88)$ or chemotherapy ( $\mathrm{HR}=0.43 ; P=0.38)$ among colon cancer patients with stage II. Likewise, chemotherapy $(\mathrm{HR}=0.26 ; P=0.34)$ and surgery

Table 2 Median Survival in Months Across the Four Stages of Cancer

\begin{tabular}{|c|c|c|c|c|c|}
\hline Characteristic & Stage I & Stage II & Stage III & Stage IV & $P$-value \\
\hline Overall & $35(16-36)$ & $21(4-24)$ & $22(15-33)$ & $16(3-26)$ & 0.111 \\
\hline Rectal cancer & - & - & $33(22-33)$ & $10(I-24)$ & 0.547 \\
\hline Colon cancer & $3 I(25-36)$ & $21(12-24)$ & $18(8-24)$ & $12(3-24)$ & 0.173 \\
\hline \multicolumn{6}{|l|}{ Gender } \\
\hline Male & $36(26-36)$ & $10(I-24)$ & $20(8-33)$ & $16(3-24)$ & 0.115 \\
\hline Female & - & $2 I(2 \mid-2 I)$ & $26(18-28)$ & $26(12-26)$ & \\
\hline \multicolumn{6}{|l|}{ Diabetes } \\
\hline Yes & - & $24(12-24)$ & $15(8-18)$ & $9(3-12)$ & $0.021 *$ \\
\hline No & $36(36-36)$ & $21(4-24)$ & $22(15-33)$ & $22(0-36)$ & \\
\hline \multicolumn{6}{|c|}{ Family History of Colorectal Cancer } \\
\hline Yes & - & - & $19(13-24)$ & $3.5(1.5-10)$ & $0.011 *$ \\
\hline No & - & $21(10-24)$ & $33(15-36)$ & $24(12-26)$ & \\
\hline
\end{tabular}

Notes: *Indicates statistically significant difference. Data are presented as median with quartile I and quartile 3 (QI-Q3). 


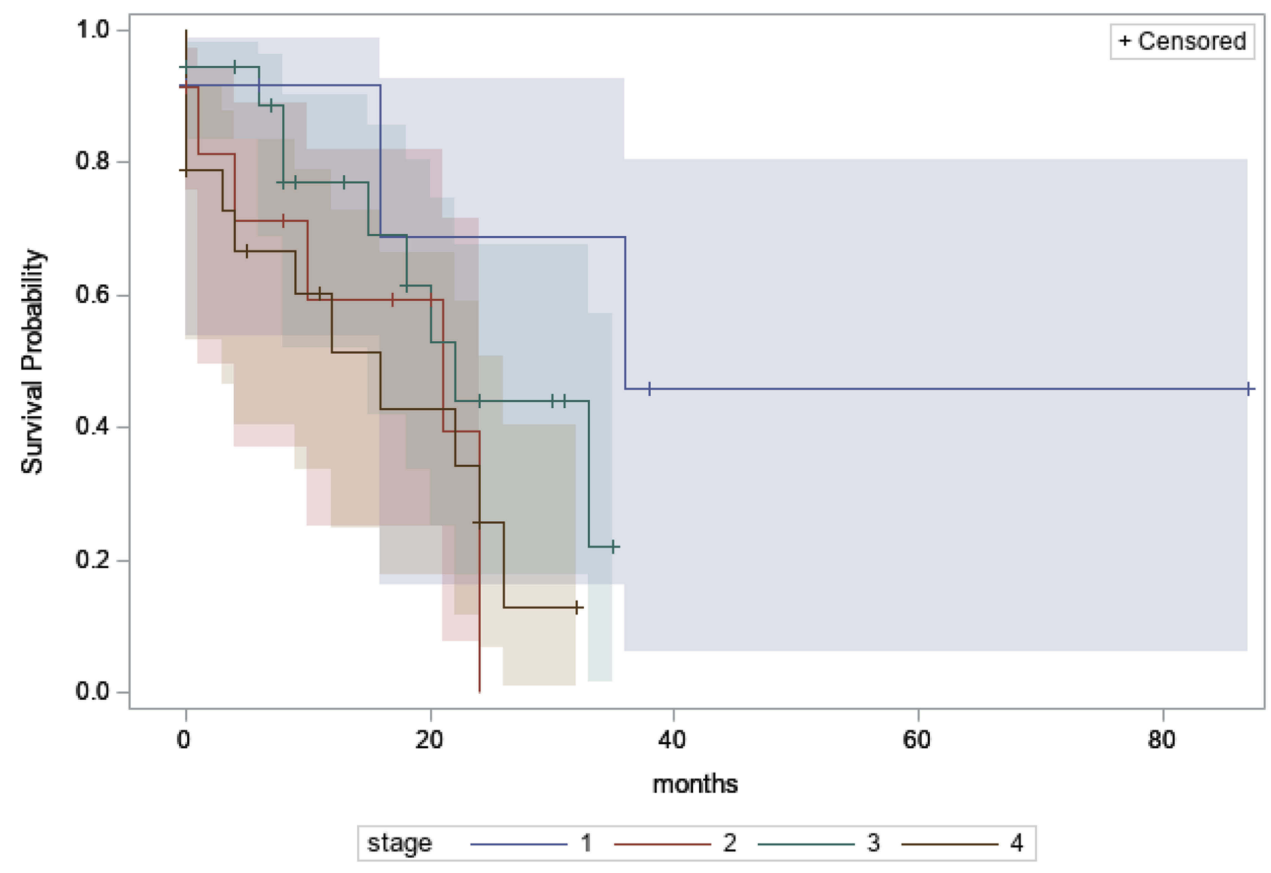

Figure 2 The survival rates among colorectal cancer patients of different stages of cancer over 36 months with $95 \%$ confidence limits.

$(\mathrm{HR}=0.67 ; P=0.73)$ were not associated with risk of mortality among stage III colon cancer patients. However, chemotherapy was significantly associated with lower risk of mortality $(\mathrm{HR}=0.33 ; P=0.03)$ among colon cancer patients in the multiple Cox proportional-hazards model as shown in Table 6.

\section{Discussion}

The current work focused on the identification of survival predictors and the risk of mortality among colorectal cancer patients subjected to different therapies. To the best of our knowledge, this is the first effort to obtain information on the predictors of survival as well as the risk of mortality among

Table 3 Kaplan-Meier Estimated Survival Probabilities Across Colon and Rectal Cancer Patients

\begin{tabular}{|l|l|}
\hline Variable & KM Survival Estimate \\
\hline Rectal Cancer & \\
Stage I & - \\
Stage II & - \\
Stage III & 0.75 I \\
Stage IV & 0.540 \\
\hline Colon Cancer & \\
Stage I & 0.583 \\
Stage II & 0.375 \\
Stage III & 0.366 \\
Stage IV & 0.120 \\
\hline
\end{tabular}

Abbreviation: KM, Kaplan-Meier. colorectal cancer patients in Saudi Arabia since 2005. The relevance of acquisition of such data is underscored by the large variability in the incidence rates of colorectal cancer worldwide, an increase in its incidence in Saudi Arabia, and the well-documented role of ethnicity in the susceptibility to this type of cancer. ${ }^{39-41}$

The major findings of this study include the demonstration that colon cancer patients who underwent chemotherapy had a significantly lower risk of mortality controlling for surgery and radiotherapy as well as a multitude of other variables (age, gender, stage of cancer, and family history of colorectal cancer). This finding is consistent with previously published research that demonstrated a favorable effect of chemotherapy among colorectal cancer patients. ${ }^{34-37}$ Colon cancer patients who underwent systemic chemotherapy as an adjuvant therapy after surgical resection of lymph nodes had significantly better survival rates compared to their counterparts who only underwent surgical resection of lymph nodes. ${ }^{34}$ Moreover, in a meta-analysis that compared the survival rates among patients with stage IV colorectal cancer with or without primary tumor resection using mostly retrospective data, patients who underwent primary tumor resection in addition to chemotherapy and radiotherapy had higher survival rates compared to those who did not receive chemotherapy. ${ }^{35}$ However, this finding was only shown among colon cancer patients in the multiple Cox 
Table 4 The Hazard Ratios of Bivariate Cox Regression of Different Variables for 36-Month Mortality Among Rectal Cancer Patients

\begin{tabular}{|l|l|l|}
\hline Variable & $\begin{array}{l}\text { Hazard Ratio (95\% } \\
\text { Confidence Interval) }\end{array}$ & $P$-value \\
\hline Surgery & $0.48(0.1 \mathrm{I}-2.2)$ & 0.35 \\
Chemotherapy & $0.39(0.08-1.74)$ & 0.22 \\
Radiotherapy & $1.00(0.01-1.2)$ & 0.99 \\
Female gender & $0.38(0.04-3.18)$ & 0.37 \\
Family history of & $16.44(0.05-20)$ & 0.99 \\
colorectal cancer & & \\
Age & $1.04(0.97-1.12)$ & 0.21 \\
Stage of cancer & $0.68(0.29-1.61)$ & 0.38 \\
\hline
\end{tabular}

Table 5 The Hazard Ratios of Bivariate Cox Regression of Different Variables for 36-Month Mortality Among Colon Cancer Patients

\begin{tabular}{|l|l|l|}
\hline Variable & $\begin{array}{l}\text { Hazard Ratio (95\% } \\
\text { Confidence Interval) }\end{array}$ & P-value \\
\hline Surgery & $0.48(0.21-1.09)$ & 0.08 \\
Chemotherapy & $0.66(0.29-1.49)$ & 0.32 \\
Radiotherapy & $1.49(0.35-6.39)$ & 0.59 \\
Female gender & $0.68(0.28-1.64)$ & 0.39 \\
Family history of & $3.14(1.21-8.13)$ & $0.02 *$ \\
colorectal cancer & & \\
Age & $0.97(0.97-1.03)$ & 0.86 \\
Stage of cancer & $1.49(0.98-2.29)$ & 0.07 \\
\hline
\end{tabular}

Note: *Indicates statistically significant difference.

Table 6 Multiple Cox-Proportional Hazard Model for 36-Month Mortality Among Colon Cancer Patients

\begin{tabular}{|l|l|l|}
\hline Variable & $\begin{array}{l}\text { Hazard Ratio (95\% } \\
\text { Confidence Interval) }\end{array}$ & P-value \\
\hline Surgery & $0.44(0.14-1.41)$ & 0.17 \\
Chemotherapy & $0.33(0.11-0.91)$ & $0.03^{*}$ \\
Radiotherapy & $1.03(0.12-9.09)$ & 0.98 \\
Female Gender & $0.99(0.38-2.59)$ & 0.97 \\
Family history of & $3.40(1.20-9.61)$ & $0.02 *$ \\
colorectal cancer & & \\
Age & $1.01(0.97-1.04)$ & 0.75 \\
Stage & $1.51(0.90-2.53)$ & 0.11 \\
\hline
\end{tabular}

Note: *Indicates statistically significant difference.

proportional-hazards model and not among rectal cancer patients due to the small number of rectal cancer patients in the study sample. Additionally, it was found that colon cancer patients with a family history of colorectal cancer had a higher risk of mortality controlling for previously mentioned variables.
The proportion of male colorectal cancer patients in the studied sample was $57.34 \%$, a percentage consistent with the results of a previous investigation utilizing the National Saudi Cancer Registry data. ${ }^{9}$ A similar tendency is also observed worldwide regardless of the incidence rate of the disease. Approximately, $60 \%$ of the reported cases in central Africa were among males, where the incidence of colorectal cancer is the lowest, and 58\% in Australia and New Zealand, where the incidence is the highest. ${ }^{42,43} \mathrm{~A}$ previous analysis has determined that during the period from 1990 to $1998,{ }^{33}$ the mean age of Saudi patients at the time of colorectal cancer diagnosis was 55.6 years for men and 52.8 for women, somewhat lower than the mean age of $59.41 \pm 12.84$ that was found in this study. It should be noted that in both the prior and the present investigations, ${ }^{33}$ the age of patients at the time of diagnosis was markedly lower than that reported in the western countries, where it averages 70 years. ${ }^{43,44}$ In addition to male sex and older age, family history of the disease, ${ }^{45,46}$ diabetes, ${ }^{47}$ hypertension, ${ }^{48}$ inflammatory bowel disease, ${ }^{49,50}$ smoking, ${ }^{51}$ and alcohol abuse, ${ }^{52}$ are often considered risk factors for colorectal cancer. In the population under study, the incidence of colorectal cancer was highest in subjects suffering from hypertension (33.33\%) and diabetes $(31.48 \%)$, reflecting the worldwide trends. ${ }^{30,43}$ Markedly, lower proportion of patients had a family history of colorectal cancer $(14.69 \%)$ and inflammatory bowel disease (2.79\%). However, due to the relatively small sample size, it cannot be definitely determined whether the lower incidence of these conditions is generalizable to the overall Saudi population of colorectal cancer patients.

The mean 36-month survival was not affected by the patient gender. However, a significant difference in survival was seen between diabetic and non-diabetic patients as well as between patients with a family history of colorectal cancer and those without. Moreover, it should be recognized that a lower likelihood of survival among the colorectal cancer that was reported in this study in comparison to previously published studies may be related to the fact that a larger percentage of patients $(62.24 \%)$ were presenting with advanced stage of cancer (stages III and IV). ${ }^{8}$

Surgery is generally considered to be the principal treatment for colorectal cancer, particularly in the absence of metastasis. ${ }^{30}$ However, surgery was not found to have a positive impact on survival in this study among either rectal or colon cancer patients, which might be due to the larger proportion of patients with advanced stages of cancer as well as the smaller sample size compared to previously published studies. ${ }^{30,32}$ The present study 
demonstrated unequivocally the benefit of chemotherapy in the management of colorectal cancer, either alone or in combination with surgery and radiotherapy. Furthermore, the results of the current analysis indicate that the prevention and management of diabetes should be incorporated as part of the efforts to decrease the negative impact of colorectal cancer on the patient survival and quality of life.

Finally, the current investigation represents the first effort in Saudi Arabia to determine the risk of mortality among colorectal cancer patients undergoing distinct treatments, controlling for multiple variables. However, some limitations of this study have to be acknowledged. First, the study had a relatively short follow-up period. In addition, the ultimate outcomes of different therapies cannot be ascertained after 36 months of follow-up. Furthermore, the analysis did not control for the tumor location due to missing data.

\section{Conclusion}

The incidence of colorectal cancer is increasing especially in low incidence areas such as Saudi Arabia. Despite the shortcomings of this study, it presents valuable information regarding the efficacy of different therapeutic protocols for colorectal cancer in this part of the world, highlighting the necessity to conduct studies with more robust designs, larger sample sizes, and longer follow-up periods to determine the clinical outcomes in patients undergoing different treatment modalities.

\section{Abbreviations}

HR, Hazard Ratio; KM, Kaplan-Meier.

\section{Data Sharing Statement}

Study data are available from the authors upon request.

\section{Acknowledgment}

The authors acknowledge financial support from the Researchers Supporting Project number (RSP-2019/16), King Saud University, Riyadh, Saudi Arabia.

\section{Author Contributions}

All authors contributed to data analysis, drafting or revising the article, gave final approval for the version to be published, and agree to be accountable for all aspects of the work.

\section{Disclosure}

The authors report no conflicts of interest in this work.

\section{References}

1. Bray F, Ferlay J, Soerjomataram I, Siegel RL, Torre LA, Jemal A. Global cancer statistics 2018: GLOBOCAN estimates of incidence and mortality worldwide for 36 cancers in 185 countries. CA Cancer J Clin. 2018;68:394-424. doi:10.3322/caac.v68.6

2. Cancer World Health Organization. World Health Organization; 2018 Available from: https://www.who.int/en/news-room/fact-sheets/ detail/cancer. Accessed January 8, 2020.

3. Siegel RL, Miller KD, Jemal A. Cancer statistics, 2019. CA Cancer J Clin. 2019;69:7-34. doi:10.3322/caac.v69.1

4. Douaiher J, Ravipati A, Grams B, Chowdhury S, Alatise O, Are C. Colorectal cancer - global burden, trends, and geographical variations. J Surg Oncol. 2017;115:619-630. doi:10.1002/jso.24578

5. Favoriti P, Carbone G, Greco M, Pirozzi F, Pirozzi RE, Corcione F. Worldwide burden of colorectal cancer: a review. Updates Surg. 2016;68:7-11. doi:10.1007/s13304-016-0359-y

6. Arnold M, Sierra MS, Laversanne M, Soerjomataram I, Jemal A, Bray F. Global patterns and trends in colorectal cancer incidence and mortality. Gut. 2017;66:683-691. doi:10.1136/gutjnl-2015-310912

7. Ibrahim EM, Zeeneldin AA, El-Khodary TR, Al-Gahmi AM, Bin Sadiq BM. Past, present and future of colorectal cancer in the Kingdom of Saudi Arabia. Saudi J Gastroenterol. 2008;14:178-182. doi:10.4103/1319-3767.43275

8. Alsanea N, Abduljabbar AS, Alhomoud S, Ashari LH, Hibbert D, Bazarbashi S. Colorectal cancer in Saudi Arabia: incidence, survival, demographics and implications for national policies. Ann Saudi Med. 2015;35:196-202. doi:10.5144/0256-4947.2015.196

9. Bazarbashi S, Al Eid H, Minguet J. Cancer incidence in Saudi Arabia: 2012 data from the Saudi cancer registry. Asian Pac J Cancer Prev. 2017;18:2437-2444. doi:10.22034/APJCP.2017.18. 9.2437

10. Reem MN, Khalid SA. Colorectal cancer: a case control study of dietary factors, King Faisal Specialist Hospital and Research Center, Riyadh, Saudi Arabia. J Family Community Med. 2008;15:57-64.

11. Sankaranarayanan R, Swaminathan R, Jayant K, Brenner H. An overview of cancer survival in Africa, Asia, the Caribbean and Central America: the case for investment in cancer health services. IARC Sci Publ. 2011;162:257-291.

12. McMichael AJ, McCall MG, Hartchorne JM, Woodings TL. Patterns of gastrointestinal cancer in European migrants to Australia: the role of dietary change. Int $J$ Cancer. 1980;5:431-437. doi:10.1002/ ijc. 2910250402

13. Vargas AJ, Thompson PA. Diet and nutrient factors in colorectal cancer risk. Nutr Clin Pract. 2012;27:613-623. doi:10.1177/ 0884533612454885

14. Al-Ahwal Mahmoud S, Shafik Yasmin H, Al-Ahwal Hazem M. First national survival data for colorectal cancer among Saudis between 1994 and 2004: what's next? BMC Public Health. 2013;13:73. doi:10.1186/1471-2458-13-73

15. Ferlay J, Colombet M, Soerjomataram I, et al. Cancer incidence and mortality patterns in Europe: estimates for 40 countries and 25 major cancers in 2018. Eur J Cancer. 2018;103:356-387. doi:10.1016/j. ejca.2018.07.005

16. van der Geest LG, Lam-Boer J, Koopman M, Verhoef C, Elferink MA, de Wilt JH. Nationwide trends in incidence, treatment and survival of colorectal cancer patients with synchronous metastases. Clin Exp Metastasis. 2015;32:457-465. doi:10.1007/s10585-015-9719-0

17. Riihimäki M, Hemminki A, Sundquist J, Hemminki K. Patterns of metastasis in colon and rectal cancer. Sci Rep. 2016;6:29765. doi:10.1038/srep29765

18. van Steenbergen LN, Elferink MA, Krijnen P, et al. Improved survival of colon cancer due to improved treatment and detection: a nationwide population-based study in The Netherlands 1989-2006. Ann Oncol. 2010;21:2206-2212. doi:10.1093/annonc/mdq227 
19. van der Pool AE, Damhuis RA, Ijzermans JN, et al. Trends in incidence, treatment and survival of patients with stage IV colorectal cancer: a population-based series. Colorectal Dis. 2012;14:56-61. doi:10.1111/codi.2011.14.issue-1

20. Adami HO, McLaughlin J, Ekbom A, et al. Cancer risk in patients with diabetes mellitus. Cancer Causes Control. 1991;2:307-314. doi:10.1007/BF00051670

21. Calle EE, Murphy TK, Rodriguez C, Thun MJ, Heath CW Jr. Diabetes mellitus and pancreatic cancer mortality in a prospective cohort of United States adults. Cancer Causes Control. 1998;9:403410. doi:10.1023/A:1008819701485

22. Will JC, Galuska DA, Vinicor F, Calle EE. Colorectal cancer: another complication of diabetes mellitus? Am J Epidemiol. 1998;147:816825. doi:10.1093/oxfordjournals.aje.a009534

23. Giovannucci E, Harlan DM, Archer MC, et al. Diabetes and cancer: a consensus report. Diabetes Care. 2010;33:1674-1685. doi:10.2337/ de $10-0666$

24. González N, Prieto I, Del Puerto-Nevado L, et al. 2017 update on the relationship between diabetes and colorectal cancer: epidemiology, potential molecular mechanisms and therapeutic implications. Oncotarget. 2017;8:18456-18485. doi:10.18632/oncotarget.v8i11

25. You JF, Hsieh LL, Changchien CR, et al. Inverse effects of mucin on survival of matched hereditary nonpolyposis colorectal cancer and sporadic colorectal cancer patients. Clin Cancer Res. 2006;12:42444250. doi:10.1158/1078-0432.CCR-06-0202

26. Dehal AN, Newton CC, Jacobs EJ, Patel AV, Gapstur SM, Campbell PT. Impact of diabetes mellitus and insulin use on survival after colorectal cancer diagnosis: the cancer prevention study-II nutrition cohort. J Clin Oncol. 2012;30:53-59. doi:10.1200/JCO.2011.38.0303

27. El Brahimi S, Smith ML, Pinheiro PS.Role of pre-existing type 2 diabetes in colorectal cancer survival among older Americans: a SEER-Medicare population-based study 2002-2011. Int J Colorectal Dis.2019;34:1467-1475. doi:10.1007/s00384-019-03345-8

28. Noh GY, Hwang DY, Choi YH, Lee YY. Effect of diabetes mellitus on outcomes of colorectal cancer. J Korean Soc Coloproctol. 2010;26:424-428. doi:10.3393/jksc.2010.26.6.424

29. Park SM, Lim MK, Shin SA, Yun YH. Impact of prediagnosis smoking, alcohol, obesity, and insulin resistance on survival in male cancer patients: National Health Insurance Corporation Study. J Clin Oncol. 2006;24:5017-5024. doi:10.1200/JCO.2006.07.0243

30. Kuipers EJ, Grady WM, Lieberman D, et al. Colorectal cancer. Nat Rev Dis Primers. 2015;1:15065. doi:10.1038/nrdp.2015.65

31. Iqbal A, George TJ. Randomized clinical trials in colon and rectal cancer. Surg Oncol Clin N Am. 2017;26:689-704. doi:10.1016/j. soc.2017.05.008

32. Pellino G, Warren O, Mills S, Rasheed S, Tekkis PP, Kontovounisios C. Comparison of Western and Asian guidelines concerning the management of colon cancer. Dis Colon Rectum. 2018;61:250-259. doi:10.1097/DCR.0000000000001012

33. Isbister WH, Murad M, Habib Z. Rectal cancer in the kingdom of Saudi Arabia: the King Faisal Specialist Hospital Experience. Aust $N$ Z J Surg. 2000;70:269-274. doi:10.1046/j.1440-1622.2000.01805.x

34. Labianca R, Milesi L, Mosconi S, Pessi MA, Beretta GD, Quadri A. The role of adjuvant chemotherapy in colon cancer. Surg Oncol. 2007;16(Suppl 1):S93-6. doi:10.1016/j.suronc.2007.10.042

35. Lee KC, Ou YC, Hu WH, Liu CC, Chen HH. Meta-analysis of outcomes of patients with stage IV colorectal cancer managed with chemotherapy/ radiochemotherapy with and without primary tumor resection. Onco Targets Ther. 2016;9:7059-7069. doi:10.2147/OTT.S112965
36. Labianca R, Nordlinger B, Beretta GD, et al. Early colon cancer: ESMO clinical practice guidelines for diagnosis, treatment and follow-up. Ann Oncol. 2013;24(Suppl 6):vi64-72. doi:10.1093/annonc/mdt354

37. Bujanda L, Sarasqueta C, Hijona E, et al. Colorectal cancer prognosis twenty years later. World $J$ Gastroenterol. 2010;16:862-867. doi:10.3748/wjg.v16.i7.862

38. Kim JH. Controversial issues in radiotherapy for rectal cancer: a systematic review. Radiat Oncol J. 2017;35:295-305. doi:10.3857/ roj.2017.00395

39. Sung JJ, Lau JY, Young GP, et al. Asia Pacific consensus recommendations for colorectal cancer screening. Gut. 2008;57:1166-1176. doi:10.1136/gut.2007.146316

40. Abu Hassan MR, Ismail I, Mohd Suan MA, et al. Incidence and mortality rates of colorectal cancer in Malaysia. Epidemiol Health. 2016;38:e2016007. doi:10.4178/epih.e2016007

41. Ladabaum U, Clarke CA, Press DJ, et al. Colorectal cancer incidence in Asian populations in California: effect of nativity and neighborhood-level factors. Am $J$ Gastroenterol. 2014;109:579-588. doi:10.1038/ ajg. 2013.488

42. Jemal A, Bray F, Center MM, Ferlay J, Ward E, Forman D. Global cancer statistics. CA Cancer J Clin. 2011;61:69-90. doi:10.3322/ caac.v61:2

43. Brenner H, Kloor M, Pox CP. Colorectal cancer. Lancet. 2014;383:1490-1502. doi:10.1016/S0140-6736(13)61649-9

44. Siegel R, DeSantis C, Virgo K, et al. Cancer treatment and survivorship statistics, 2012. CA Cancer J Clin. 2012;62:220-241. doi:10. 3322/caac.v62:4

45. Taylor DP, Burt RW, Williams MS, Haug PJ, Cannon-Albright LA. Population-based family history-specific risks for colorectal cancer: a constellation approach. Gastroenterology. 2010;138:877-885. doi:10.1053/j.gastro.2009.11.044

46. Jansson-Knodell CL, Foster NR, Sargent DJ, et al. Family history of colorectal cancer and its impact on survival in patients with resected stage III colon cancer: results from NCCTG Trial N0147 (Alliance). $J$ Gastrointest Oncol. 2017;8:1-11. doi:10.21037/jgo

47. Guraya SY. Association of type 2 diabetes mellitus and the risk of colorectal cancer: a meta-analysis and systematic review. World $J$ Gastroenterol. 2015;21:6026-6031. doi:10.3748/wjg.v21.i19.6026

48. Seretis A, Cividini S, Markozannes G, et al. Association between blood pressure and risk of cancer development: a systematic review and meta-analysis of observational studies. Sci Rep. 2019;9:8565. doi:10.1038/s41598-019-45014-4

49. Jess T, Rungoe C, Peyrin-Biroulet L. Risk of colorectal cancer in patients with ulcerative colitis: a meta-analysis of population-based cohort studies. Clin Gastroenterol Hepatol. 2012;10:639-645. doi:10.1016/j.cgh.2012.01.010

50. Herrinton LJ, Liu L, Levin TR, Allison JE, Lewis JD, Velayos F. Incidence and mortality of colorectal adenocarcinoma in persons with inflammatory bowel disease from 1998 to 2010. Gastroenterology. 2012;143:382-389. doi:10.1053/j.gastro.2012.04.054

51. Liang PS, Chen TY, Giovannucci E. Cigarette smoking and colorectal cancer incidence and mortality: systematic review and meta-analysis. Int J Cancer. 2009;124:2406-2415. doi:10.1002/ijc.24191

52. Fedirko V, Tramacere I, Bagnardi V, et al. Alcohol drinking and colorectal cancer risk: an overall and dose-response metaanalysis of published studies. Ann Oncol. 2011;22:1958-1972. doi:10.1093/ annonc/mdq653 


\section{Publish your work in this journal}

Cancer Management and Research is an international, peer-reviewed open access journal focusing on cancer research and the optimal use of preventative and integrated treatment interventions to achieve improved outcomes, enhanced survival and quality of life for the cancer patient.
The manuscript management system is completely online and includes a very quick and fair peer-review system, which is all easy to use. Visit http://www.dovepress.com/testimonials.php to read real quotes from published authors.

Submit your manuscript here: https://www.dovepress.com/cancer-management-and-research-journal 